\title{
Spatiotemporal expression of the serine protease inhibitor, SERPINE2, in the mouse placenta and uterus during the estrous cycle, pregnancy, and lactation
}

\author{
Schu-Rern Chern ${ }^{1,2+}$, Sheng-Hsiang Li ${ }^{2,3+}$, Chung-Hao Lu' ${ }^{2}$ Edmund I Tsuen Chen ${ }^{1 *}$
}

\begin{abstract}
Background: SERPINE2, also known as glia-derived nexin or protease nexin-1, belongs to the serine protease inhibitor (SERPIN) superfamily. It is one of the potent serpins that modulates the activity of the plasminogen activator (PA) and was implicated in tissue remodeling. In this study, we investigated the expression patterns of SERPINE2 in the mouse placenta and uterus during the estrous cycle, pregnancy, and lactation.

Methods: SERPINE2 was purified from mouse seminal vesicle secretion using liquid chromatography (LC) and identified by LC/tandem mass spectrometry. The antiserum against the SERPINE2 protein was raised in rabbits. To reveal the uterine and placental expression of SERPINE2, tissues at various stages were collected for real-time PCR quantification, Western blotting, and immunohistochemical staining.

Results: Serpine2 mRNA was the major PA inhibitor in the placenta and uterus during the estrous cycle, pregnancy, and lactation, although Serpine1 mRNA had higher expression levels than Serpine2 mRNA in the placenta. Plat seemed to be the major PA in the mouse uterus and placenta. Antiserum against the SERPINE2 protein specifically recognized two forms of SERPINE2 and an extra 75-kDa protein, which was probably a complex of SERPINE2 with a certain protease, from among thousands of protein components in the tissue extract as demonstrated by Western blotting. In the uterus, SERPINE2 was primarily localized in luminal and glandular epithelial cells but it also was detected in circular and longitudinal smooth muscle cells during the estrous cycle and lactation. It was prominently expressed in decidual stroma cells, the metrial gland, and endometrial epithelium of the pregnant uterus. In the placenta, SERPINE2 was expressed in trophoblasts of the labyrinth and spongiotrophoblasts. However, its expression was remarkably reduced in giant cells which existed in the giant cell-decidual junction zone. In contrast, prominent expression of SERPINE2 seemed to be detected on clusters of glycogen cells near the junction zone. In addition, yolk sac membranes also showed high expression of SERPINE2.
\end{abstract}

Conclusions: These findings indicate that SERPINE2 is a major PA inhibitor in the placenta and uterus during the estrous cycle, pregnancy, and lactation. It may participate in the PA-modulated tissue remodeling process in the mouse placenta and uterus.

\footnotetext{
* Correspondence: chenit@ym.edu.tw

+ Contributed equally

'Department of Biotechnology and Laboratory Science in Medicine, National

Yang-Ming University, Taipei, Taiwan

Full list of author information is available at the end of the article
} 


\section{Background}

The mammalian uterus undergoes drastic tissue remodeling during the estrous cycle, implantation, and pregnancy. Tissue remodeling requires a fine-tuned balance between levels of proteases and their cognate inhibitors. The plasminogen activator (PA) system refers to the PA and its cognate inhibitors [1]. The PA is involved in tissue remodeling by converting abundant extracellular plasminogen into plasmin, an active protease, which degrades the extracellular matrix. The classical substrate of plasmin is fibrin, in fact, most other matrix proteins can be cleaved by this enzyme [1]. So far, two forms of PA, tissue-type (PLAT) and urokinase-type (PLAU) are reported. The activity of PA is modulated by several protease inhibitors that belong to the serine protease inhibitor (SERPIN) superfamily, such as SERPINA5, SERPINB2, SERPINE1, and SERPINE2 [2].

The PA system is associated with many physiological processes, including ovulation, embryogenesis, and embryo implantation in female reproductive tissues [1,3], and pathological processes, such as neoplasia [1]. How SERPIN modulates the proteolytic activities of PLAT/PLAU in reproductive tissue remodeling is of great importance.

The expression and activity of PLAT and PLAU were detected in female reproductive tissues, including the endometrium during cycling [4,5], implantation [6], and placentation [7-10]. Also, PLAU was found to be expressed during mouse placental development [10].

SERPINE1 was demonstrated to be present in human and mouse uteri during implantation [6,11], indicating that the PA inhibitor is involved in implantation. It was also detected in the placenta $[8,9]$. However, few studies have examined uterine SERPINE2 expression. SERPINE2, also known as glia-derived nexin or protease nexin-1, has broad anti-protease activity specific to serine proteases, including trypsin, thrombin, plasmin, prostasin [12], and PLAU [13]. It is widely expressed in various tissues [14]. Lin et al. reported that expression levels of SERPINE2 in the monkey endometrium and placenta during early pregnancy were weak or below the level of detection [15]. On the contrary, SERPINE2 was highly expressed in the human placenta throughout pregnancy [16]. In rats, Serpine 2 mRNA was exclusively detected in endometrial stromal cells of the uterus, in particular on day 6.5 postcoitally, thus suggesting that it may be involved in the implantation process [17]. It seems that different species have different expression patterns for the Serpine 2 gene. So far, no comprehensive study has exactly determined the expression of SERPINE2 in the murine placenta and uterus during the estrous cycle, pregnancy, and lactation. We therefore conducted this investigation to reveal the placental and uterine expression of the Serpine 2 gene and the cellular localization of SERPINE2 protein in mice.

\section{Methods}

\section{Animals and tissue collection}

Specific pathogen-free outbred ICR mice were bred and maintained in the Animal Center of the Department of Medical Research, Mackay Memorial Hospital. Animals were treated according to institutional guidelines for the care and use of experimental animals. They were housed under controlled lighting ( $14 \mathrm{~h}$ of light, $10 \mathrm{~h}$ of dark) at $21 \sim 22^{\circ} \mathrm{C}$ and were provided with water and NIH-31 laboratory chow ad libitum. Normal 12-week-old adult male mice were used to purify the SERPINE2 protein as previously described [18]. The estrous cycle was staged by examining vaginal smears as described by Rugh [19]. The vaginal impedance was monitored by the MK-10A impedance checker (Muromachi Kikai, Tokyo, Japan) to work as a reference prior to doing vagina smear. The electric resistance of vagina has been used for determination of rat estrous cycle [20]. It also was useful for mouse to monitor the distinct phase of estrous cycle. The day when the vaginal plug was observed was designated day 0.5 of pregnancy. To investigate Serpine 2 mRNA and protein expression in the placenta and uterus at various physiological stages, adult non-pregnant and pregnant female mice were sacrificed and their tissues removed. For each mouse, part of the tissue was stored in liquid nitrogen for mRNA and protein analyses, and another part was fixed in $10 \%(\mathrm{v} / \mathrm{v})$ formaldehyde for the immunohistochemical analysis.

\section{RNA isolation, reverse transcription, and real-time polymerase chain reaction (PCR)}

Total RNA was extracted from tissue homogenates treated with DNase I using an RNeasy Mini kit (Qiagen, Valencia, CA, USA). Five micrograms of total RNA was then reverse-transcribed into a 20 - $\mu$ l first-strand complementary (c)DNA pool using a High-Capacity cDNA Archive Kit (Applied Biosystems, Foster City, CA, USA) according to the manufacturer's instructions.

To examine Serpin gene expression, the real-time PCR was conducted. PCR primers (Table 1) were designed to cross the junction between the exon and intron. We used the hypoxanthine guanine phosphoribosyltransferase (Hprt) gene as the internal loading control to normalize the relative gene expression levels.

Samples $(n=4$ or 5$)$ at each stage were separately analyzed. The PCR amplification efficiency for each gene was tested to ensure that it was equivalent to that of Hprt mRNA examined in a cDNA dilution series. The PCR was performed in a total volume of $20 \mu \mathrm{l}$, containing $50 \mathrm{ng}$ of tissue cDNA, $150 \mathrm{nM}$ each of the forward 


\begin{tabular}{|c|c|c|c|c|}
\hline Gene $^{a}$ & Primer & Sequence & Position & Product size $(\mathrm{bp})$ \\
\hline \multicolumn{5}{|l|}{ Serpina5 } \\
\hline & $F^{b}$ & 5'-TCTCCATTGAGGCTACCTACAAACT-3' & 1071-1095 & \\
\hline & $\mathrm{R}^{c}$ & 5'-GTGCACCATCTCAGACAACTTGA-3' & $1201-1179$ & 131 \\
\hline \multicolumn{5}{|l|}{ Serpinb2 } \\
\hline & $\mathrm{F}$ & 5'-TTCCGTGTGAACTCGCATGA-3' & $664-683$ & \\
\hline & $\mathrm{R}$ & 5'-GGAAGCAACAGGAGCATGCT-3' & $806-787$ & 143 \\
\hline \multicolumn{5}{|l|}{ Serpine1 } \\
\hline & $\mathrm{F}$ & 5'-CAGAGCAACAAGTTCAACTACACTGA-3' & $810-835$ & \\
\hline & $\mathrm{R}$ & 5'-CAGCGATGAACATGCTGAGG-3' & $915-896$ & 106 \\
\hline \multicolumn{5}{|l|}{ Serpine2 } \\
\hline & $\mathrm{F}$ & 5'-CAGATCATCAAGTCACGGCCT-3' & $269-289$ & \\
\hline & $\mathrm{R}$ & 5'-ACCGTGGAGAGCTGCTTCTIT-3' & $387-367$ & 119 \\
\hline \multicolumn{5}{|l|}{ Plat } \\
\hline & $\mathrm{F}$ & 5'-AAGAGAGCAGCTCTGTTGGCAC-3' & 1366-1387 & \\
\hline & $\mathrm{R}$ & 5'-AATGGAGACGATGCCTCATGC-3' & $1477-1457$ & 112 \\
\hline \multicolumn{5}{|l|}{ Plau } \\
\hline & $\mathrm{F}$ & 5'-GAAGCGACCCTGGTGCTATG-3' & $445-464$ & \\
\hline & $\mathrm{R}$ & 5'-TTGCTAAGAGAGCAGTCATGCA-3' & $526-504$ & 82 \\
\hline \multicolumn{5}{|l|}{ Hprt } \\
\hline & $\mathrm{F}$ & 5'-GAATCACGTTTGTGTCATTAGTGAAA-3' & $752-777$ & \\
\hline & $\mathrm{R}$ & 5'-TGCGCTCATCTTAGGCTTTGTA-3' & 813-792 & 62 \\
\hline
\end{tabular}

a GenBank accession nos.: Serpina5, NM_172953; Serpinb2, NM_011111; Serpine1, NM_008871; Serpine2, NM_009255; Plat, NM_008872; Plau, NM_008873; Hprt, NM_013556.

${ }^{b} \mathrm{~F}$, forward primer.

${ }^{\mathrm{C}} \mathrm{R}$, reverse primer.

and reverse primers, and $10 \mu \mathrm{l}$ of $2 \times$ SYBR Green Master Mix (Applied Biosystems). All reactions were performed in triplicate and run on an ABI/PRISM 7500 Fast Sequence Detector System (Applied Biosystems) under the following conditions: $50^{\circ} \mathrm{C}$ for $2 \mathrm{~min}, 95^{\circ} \mathrm{C}$ for $10 \mathrm{~min}$, and then 40 cycles at $95^{\circ} \mathrm{C}$ for $15 \mathrm{~s}$ and $60^{\circ} \mathrm{C}$ for $1 \mathrm{~min}$. The threshold cycle $(\mathrm{Ct})$ was defined as the fractional cycle number at which the reporter fluorescence, i.e., the number of amplified copies, reached a fixed threshold. A melting curve analysis was run to verify that only a single product had formed in the reaction. The identity of the PCR products was confirmed by DNA sequencing. Relative quantification of mRNA expression was calculated by the $2^{-\Delta \Delta C t}$ method [21].

\section{Protein purification and identification}

To obtain the pure antigen to produce a highly specific and sensitive antiserum, the native SERPINE2 protein was purified from the mouse seminal vesicle secretion (SVS), since the mouse seminal vesicle prominently expresses SERPINE2 [14]. Adult male mice (10 12 weeks old) were sacrificed by cervical dislocation. The SVS was collected, centrifuged, and fractionated successively by ion-exchange chromatography on a diethylaminoethyl Sephacel (GE Healthcare Life Sciences, Piscataway, NJ, USA) column and gel-filtered on a
Sephadex G-75 (GE Healthcare Life Sciences) column as previously described [18]. Peak 2 eluted from the Sephadex G-75 column was further subjected to ion-exchange high-performance liquid chromatography (HPLC) on a Protein PAK SP 5PW (Waters, Milford, MA, USA) column $(7.5 \mathrm{~cm} \times 7.5 \mathrm{~mm})$. The column was eluted with a linear gradient of $0 \% \sim 60 \%(\mathrm{w} / \mathrm{v}) 1.0 \mathrm{M} \mathrm{NaCl}$ in $20 \mathrm{mM}$ sodium acetate at $\mathrm{pH} 6.0$ at a flow rate of $1.0 \mathrm{ml} / \mathrm{min}$ for $50 \mathrm{~min}$. The chromatogram is shown in Additional file 1, Figure S1. The protein concentration was determined using a bicinchoninic acid protein assay kit (Pierce, Rockford, IL, USA). The purified protein was identified by sodium dodecylsulfate polyacrylamide gel electrophoresis (SDS-PAGE) on a $15 \%$ gel slab $(8.2 \times$ $7.3 \times 0.075 \mathrm{~cm})$. Protein bands on the SDS-PAGE gel were excised and subjected to in-gel digestion with trypsin following our previously described method [22]. The result is shown in Additional file 1, Figure S1.

\section{Production of the specific antiserum}

Antisera against SERPINE2 were produced in New Zealand white rabbits. The purified protein in normal saline $(0.4 \mathrm{mg} / \mathrm{ml})$ was emulsified with Freund's complete adjuvant (1:1, v/v) (Sigma-Aldrich, St. Louis, MO, USA). In total, $2 \mathrm{ml}$ of the mixture was injected subcutaneously in multiple sites in a rabbit. Two rabbits were 
boosted twice every 3 weeks with the mixture of the same amount of purified protein and Freund's incomplete adjuvant (1:1, v/v) (Sigma-Aldrich). Antiserum was collected 10 days after the last injection.

Two hundred micrograms of the purified SERPINE2 protein was conjugated to AminoLink beads according to the manufacturer's instructions (Pierce). Antisera against SERPINE2 were adsorbed by the conjugated beads to remove the specific antibody against SERPINE2. The treated antiserum was used as the control antiserum.

\section{Western blotting}

Tissue extract proteins were resolved using SDS-PAGE on a $10 \%$ gel slab $(8.2 \times 7.3 \times 0.075 \mathrm{~cm})$ and were transferred to a nitrocellulose membrane for immunostaining according to a previously described method [23]. Membranes were blocked with $10 \%(\mathrm{w} / \mathrm{v})$ skim milk in phosphate-buffered saline (PBS) (blocking solution) for $2 \mathrm{~h}$, and then incubated with anti-SERPINE2 antiserum (1: 5000 ) or monoclonal anti- $\alpha$-tubulin (1: 15,000 , SigmaAldrich) in blocking solution for $1 \mathrm{~h}$ at room temperature. After gentle agitation in four changes of PBS for $15 \mathrm{~min}$ each, they were immunoreacted with horseradish peroxidase (HRP)-conjugated goat anti-rabbit immunoglobulin G (IgG) (1: 10,000, GE Healthcare Life Sciences) or HRP-conjugated anti-mouse IgG (1: 15,000; Cell Signaling Technology, Beverly, MA, USA) in blocking solution for $1 \mathrm{~h}$. Immunoreactive bands were revealed using an enhanced chemiluminescent (ECL) substrate according to the manufacturer's instructions (Pierce).

\section{Immunohistochemical staining}

Tissues were collected, fixed in formalin, embedded in paraffin, and cut into $5-\mu \mathrm{m}$ sections. After the slides were deparaffinized and hydrated, they were placed in a plastic slide holder filled with the antigen retrieval AR10 solution (BioGenex, San Ramon, CA, USA), soaked in a $70^{\circ} \mathrm{C}$ water bath, rapidly boiled to $>95^{\circ} \mathrm{C}$, and maintained for $15 \mathrm{~min}$. While cooling to room temperature for $30 \mathrm{~min}$, the slides were treated with $3 \%(\mathrm{v} / \mathrm{v})$ $\mathrm{H}_{2} \mathrm{O}_{2}$ in PBS for 15 min, blocked with $10 \%$ (v/v) normal goat serum in PBS (blocking solution) for $1 \mathrm{~h}$ at room temperature, and then incubated with anti-SERPINE2 antiserum or antiserum pretreated with SERPINE2-conjugated beads diluted 1: 700 in the blocking solution at $4^{\circ} \mathrm{C}$ for $16 \mathrm{~h}$. After washing, the slides were treated with biotin-conjugated goat anti-rabbit IgG $(\sim 3 \mu \mathrm{g} / \mathrm{ml})$ (Zymed Laboratories, South San Francisco, CA, USA) in blocking solution for $1 \mathrm{~h}$ at room temperature. The slides were washed again and then incubated with HRPconjugated streptavidin $(\sim 1 \mu \mathrm{g} / \mathrm{ml})$ (Zymed Laboratories) in blocking solution for $40 \mathrm{~min}$ at room temperature. Protein signals were detected by 3 -amino9-ethylcarbazole staining (Zymed Laboratories). The slides were then counterstained with hematoxylin (Vector Laboratories, Burlingame, CA, USA) and photographed using a Zeiss AxioImager Z1 microscope system equipped with CCD camera and an automated acquisition system (TissueGnostics, Vienna, Austria).

\section{Statistical analysis}

Data are presented as the mean \pm standard deviation (SD). Differences were analyzed by the one-way analysis of variance (ANOVA) followed by Bonferroni post hoc test using InStat software (GraphPad, San Diego, CA, USA). A $p$ value of $<0.05$ was considered significant.

\section{Results}

Expression of the SERPINE2 protein in the mouse uterus during the estrous cycle

We analyzed the gene expression of PAs and their cognate inhibitors, i.e., Serpina5, Serpinb2, Serpine1, and Serpine2, in the mouse uterus during the estrous cycle by real-time PCR. As shown in Figure 1A, Plat mRNA was apparently the most highly expressed PA in the mouse uterus. Serpinea 5 and Serpinb2 had very minor signals or were not detected. However, Serpine 2 mRNA was the most prominently expressed PA inhibitor, while Serpine1 mRNA was next. Serpine 2 mRNA's expression was significant among PA inhibitors examined in the cycling uterus, being especially prominent in metestrus and diestrus uteri.

To produce specific antibodies, we purified the SERPINE2 protein from the SVS (see "Methods" and Additional file 1 for details) as the antigen. As revealed by Western blotting, the antiserum against SERPINE2 recognized the purified 43-kDa band. Two forms, about 40- and 42-kDa bands, of SERPINE2 were detected from thousands of protein components in the uterine tissue extract collected from different phase of estrous cycle (Figure 1B, arrows). An approximately $75-\mathrm{kDa}$ band was also seen at the four stages of the cycling uterus (Figure 1B, arrowhead). The $75-\mathrm{kDa}$ band was probably the complex of SERPINE2 and its cognate protease, which were demonstrated in previous studies $[12,14,24,25]$. Thus, two forms of SERPINE2 and an extra 75-kDa SERPINE2-protease complex were expressed in the mouse uterus. No signal was seen (data not shown) when the antiserum was removed from the blots and reprobed with the antiserum that was pretreated with SERPINE2-conjugated beads (control antiserum), indicating the high specificity of the antibody.

To reveal the cellular localization of the SERPINE2 protein in the mouse uterus during the estrous cycle, an immunolocalization study was conducted using specific anti-SERPINE2 antiserum. The SERPINE2 protein was 

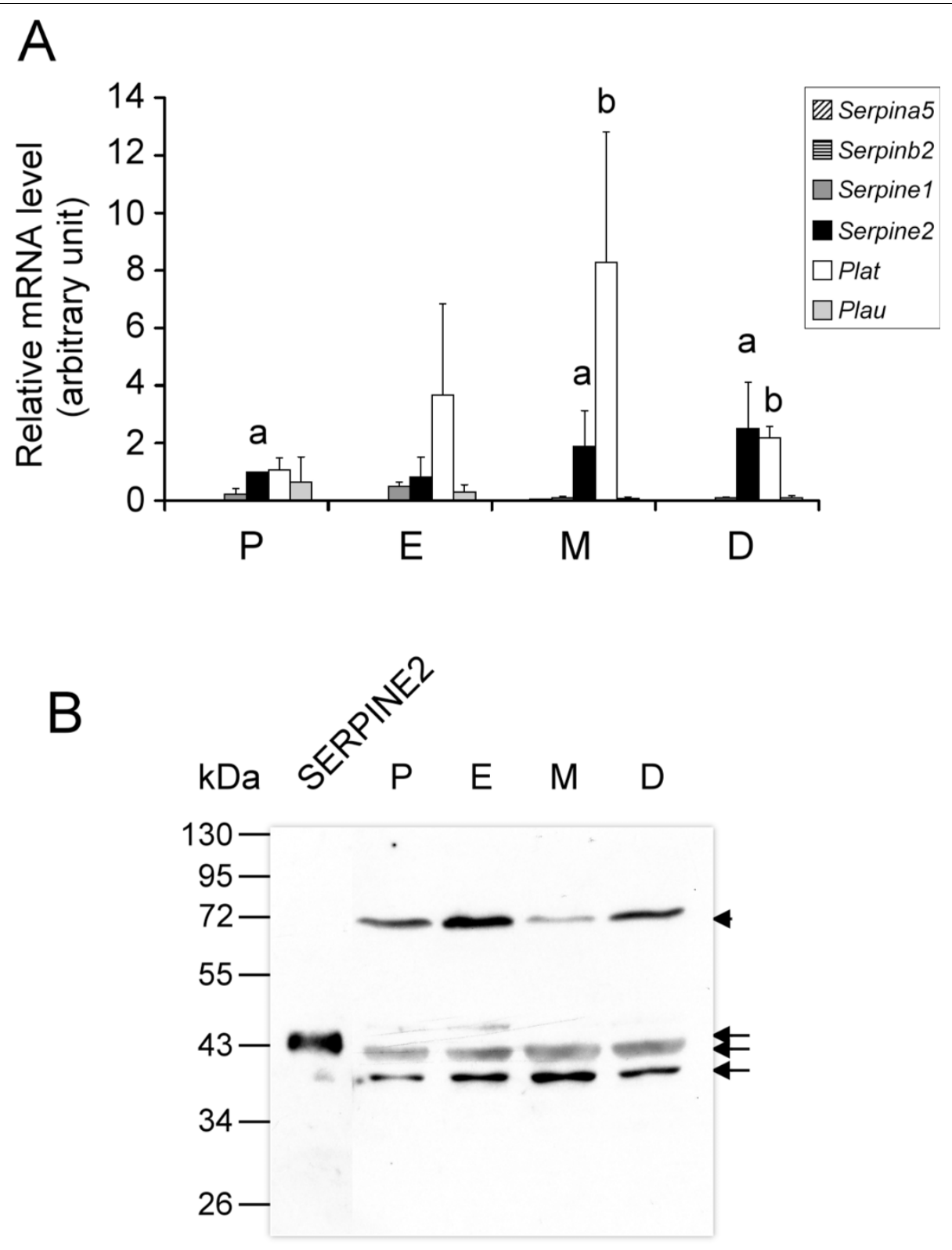

\section{Tubulin}

Figure 1 Expression of the plasminogen activator (PA) and PA inhibitors in the mouse uterus during the estrus cycle. (A) Real-time PCR was conducted to evaluate gene expression levels. Relative levels of mRNA were normalized to Hprt mRNA levels. Data are presented as the mean of four individual experiments, and error bars represent the standard deviation (SD). ${ }^{\text {a }}$ Significant difference compared to other Serpin mRNA levels $(p<0.05)$. ${ }^{b}$ Significant difference compared to Plau mRNA levels $(p<0.001)$. (B) Expression of the SERPINE2 protein in the cycling uterus. Forty-five micrograms of total protein prepared from the homogenates of uterine tissue at proestrus ( $P$, lane 2), estrus ( $E$, lane 3), metestrus ( $M$, lane 4$)$, and diestrus stages ( $D$, lane 5 ) was analyzed by Western blotting. The purified SERPINE2 protein (30 ng) was loaded as the positive control (lane 1). The arrowhead indicates a possible protein complex of SERPINE2 and a certain protease. Arrows indicate the isoform proteins of SERPINE2. The $\alpha$-tubulin protein level is shown as the loading control.

primarily immunolocalized to luminal and glandular epithelial cells and was weakly expressed in circular and longitudinal smooth muscle cells at proestrus, estrus and diestrus, but was nearly undetectable at metestrus.
Signals from stromal cells were relatively weaker (Figure $2 \mathrm{~A}, \mathrm{~B}, \mathrm{E}$ ) except at metestrus (Figure 2D). However, when slides were immunostained with control antiserum, no signal was detected (Figure 2C). 


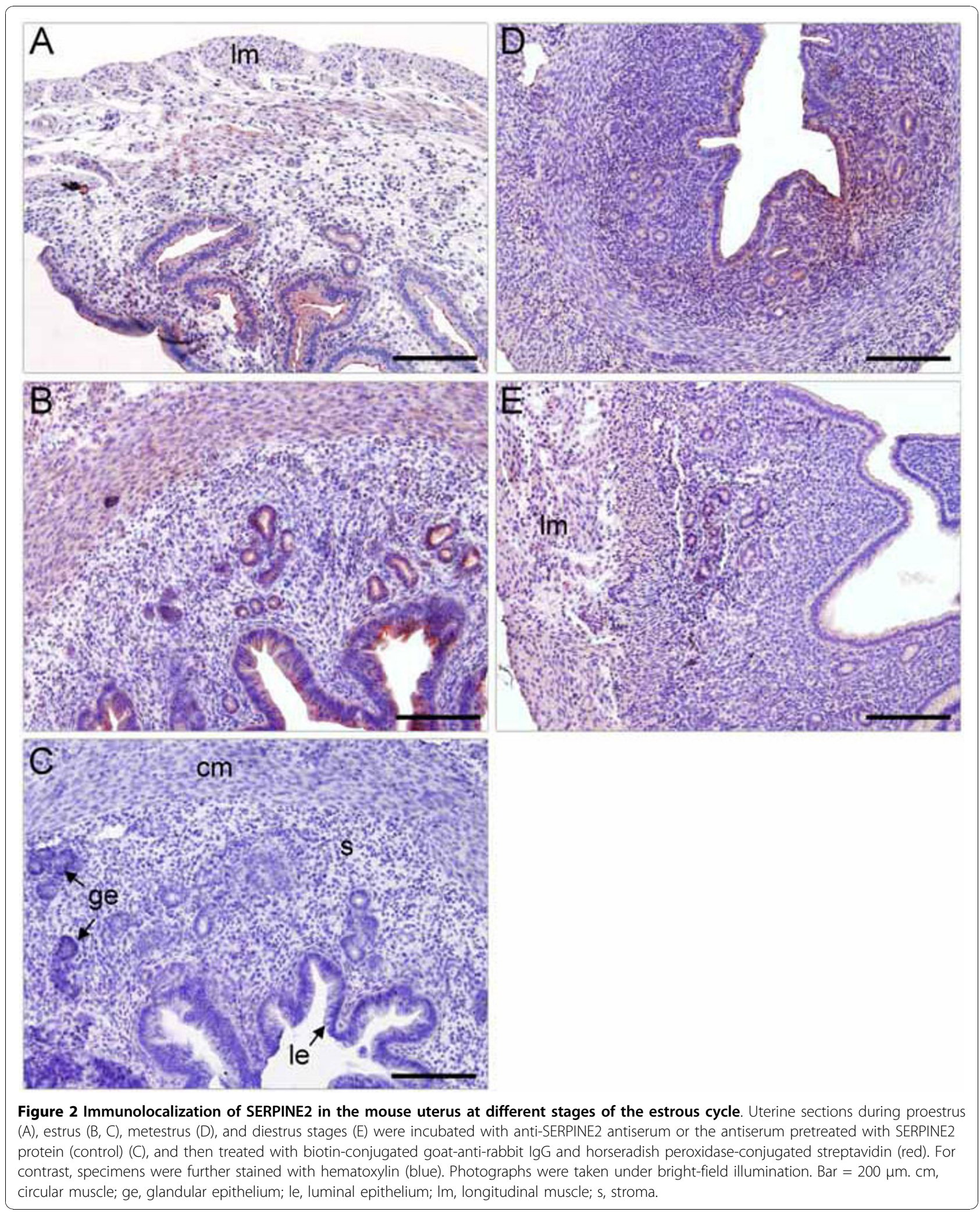




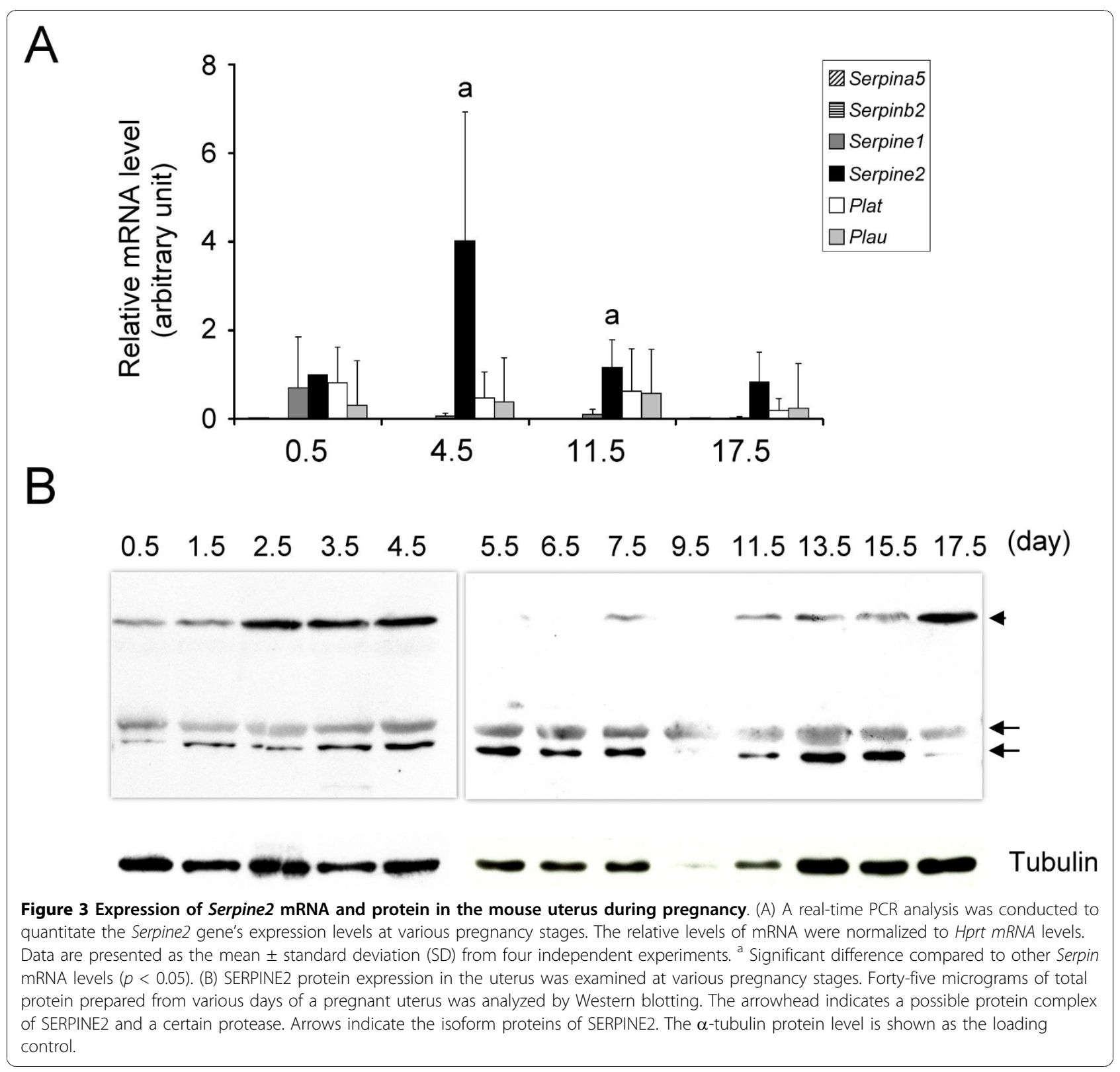

Expression of the SERPINE2 protein in the mouse uterus and placenta during pregnancy

To assess the gene expression of PAs and PA inhibitors in the pregnant uterus, a quantitative real-time PCR was performed using several stages of uterine tissues during pregnancy. As shown in Figure 3A, among the PA inhibitors, Serpine 2 mRNA seemed to be most highly expressed in the pregnant uterus, while Plat and Plau mRNA showed no differences in expression levels among the different stages examined. The SERPINE2 protein was detected at various stages in the pregnant uterus by Western blotting. The $75-\mathrm{kDa}$ protein was again detected in uterine tissues (Figure $3 \mathrm{~B}$ ). These findings confirm the expression of Serpine 2 mRNA and protein in the gravid uterus.

Uterine expression of SERPINE2 was detected early in the pregnancy of mice (Figure 4). On days 0.5 and 4.5, SERPINE2 was primarily expressed in luminal and glandular epithelia, while a visible protein signal was also detected in the circular and longitudinal layers of the myometrium (Figure $4 \mathrm{AB}$ ). It should be noted that stronger protein expression was found during the implantation period on day 4.5 of pregnancy (Figure $4 B$ ). On day 5.5, SERPINE2 was prominently expressed in stromal cells during decidualization (data not shown). On day 7.5 , trophoblast giant cells appeared among 


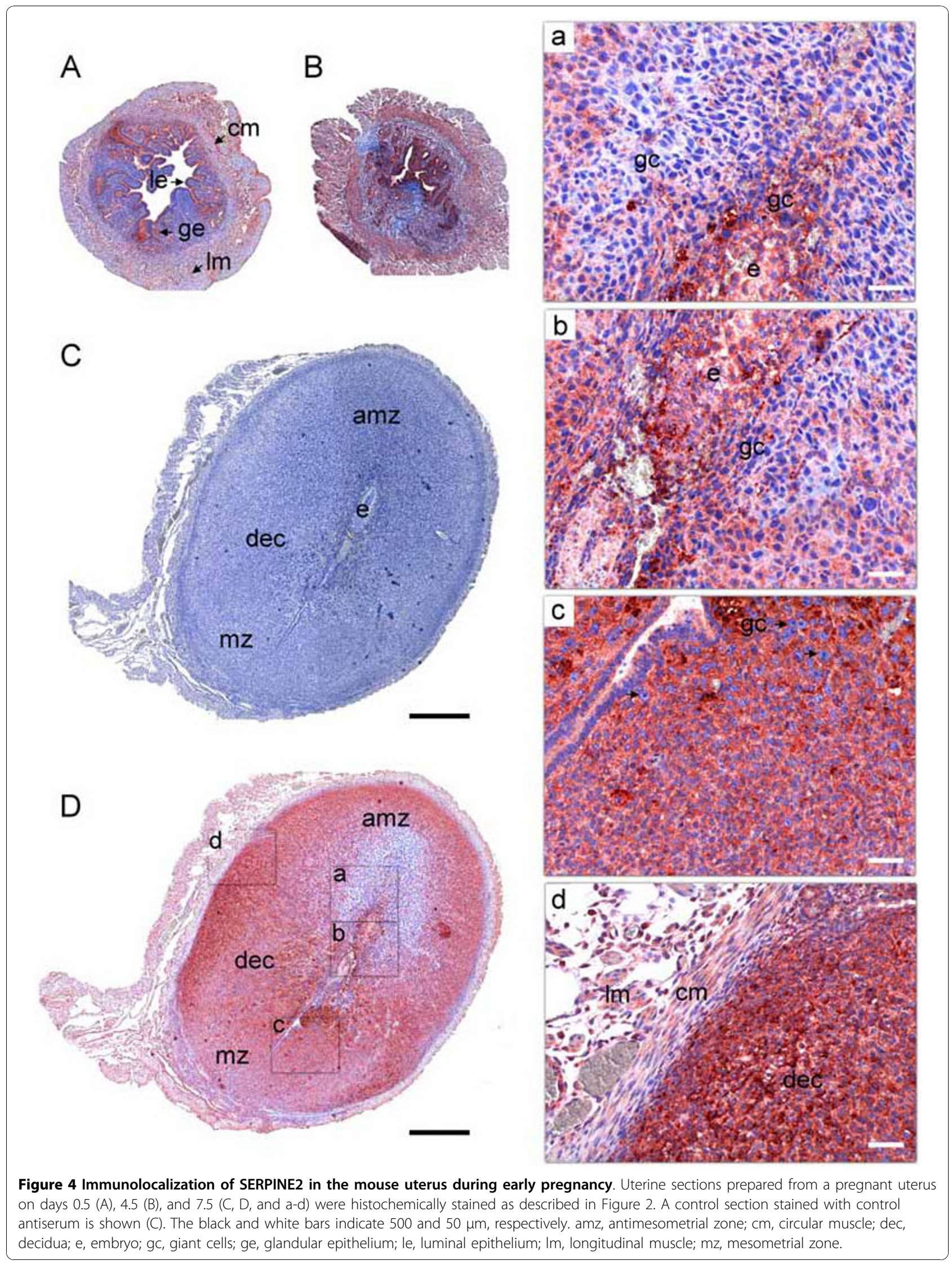



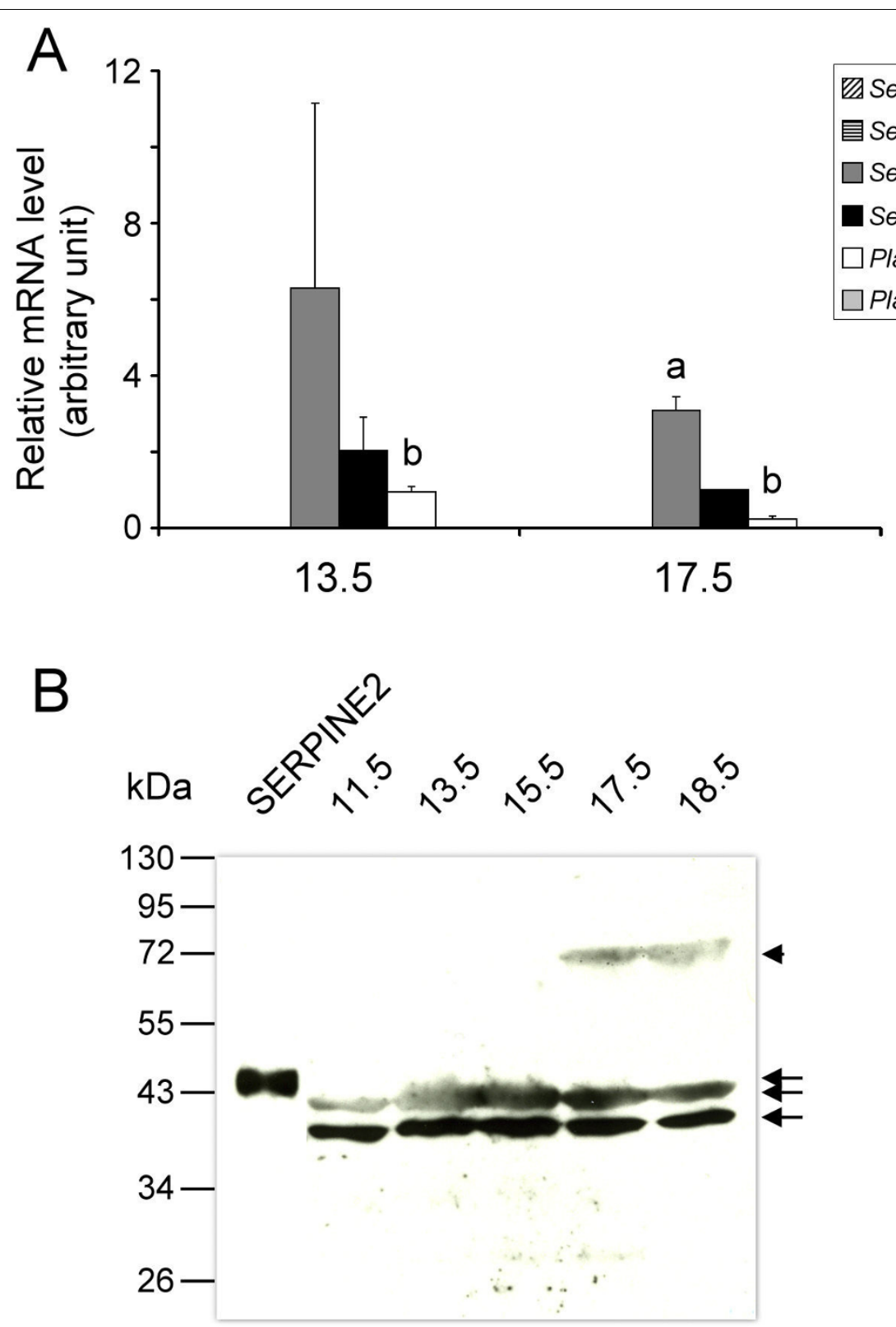

Figure 5 Expression of Serpine2 mRNA and protein in the placenta. (A) Placental expression of Serpine2 mRNA. Quantitative real-time PCR was conducted to analyze gene expression levels. The relative levels of mRNA were normalized to Hprt mRNA levels. Data are presented as the mean of three individual experiments, and error bars represent the standard deviation (SD). ${ }^{\text {a }}$ Significant difference compared to Serpine2 mRNA levels $(p<0.001){ }^{b}$ Significant difference compared to Plau mRNA levels $(p<0.001)$. (B) Placental SERPINE2 expression. Forty-five micrograms of total protein prepared from the homogenates of placental tissue was analyzed by Western blotting. The arrowhead indicates a possible protein complex of SERPINE2 and a certain protease. Arrows indicate the isoform proteins of SERPINE2. The $\alpha$-tubulin protein level is shown as the loading control.

decidual stromal cells in the antimesometrial zone; however, their SERPINE2 protein expression was obviously weaker (Figure 4D). Trophoblast giant cells that stemmed from the embryo invaded decidual cells (Figure 4D, a, b). Giant cells that appeared in the antimesometrial zone showed significantly weaker SERPINE2 protein expression, while the situation was opposite in the mesometrial zone (Figure $4 \mathrm{D}$, c). In contrast to the antimesometrial stroma, the mesometrial stroma strongly expressed SERPINE2. In addition to prominent 


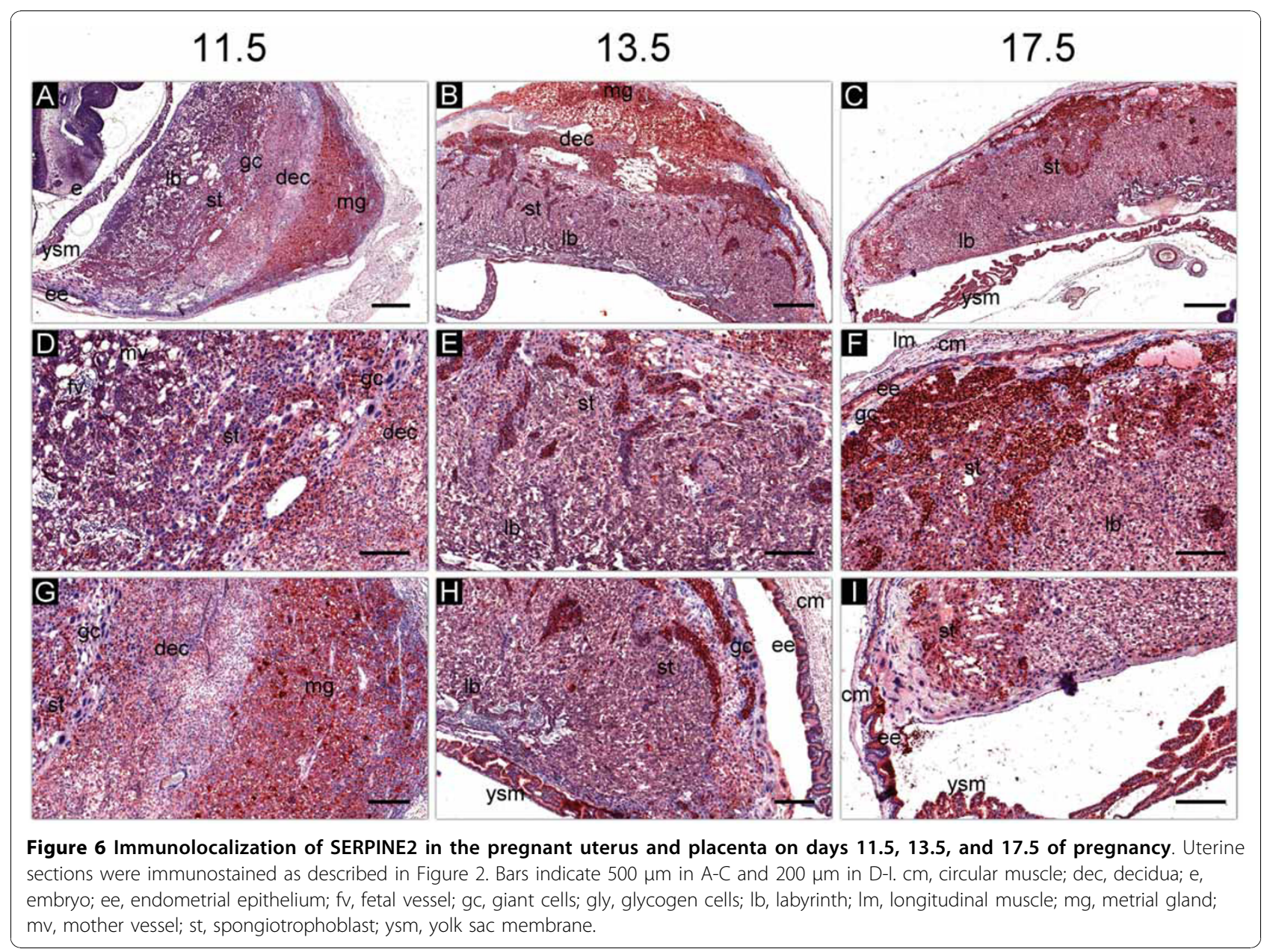

SERPINE2 expression in decidual cells, visible signals were seen in the circular and longitudinal layers of the myometrium (Figure 4D, d).

In the placenta, Plat mRNA seemed to be the most highly expressed PA as demonstrated by a quantitative real-time PCR (Figure 5A). Serpinea5 and Serpinb2 mRNAs were almost not detected, while Serpine1 mRNA was more highly expressed than was Serpine2 mRNA (Figure 5A). The SERPINE2 protein was also detected in the placenta by Western blotting (Figure 5B).

SERPINE2 was expressed in various cells in the placenta and uterus during mid- and late-pregnancy. In the uterus, it was prominently expressed in the decidua, metrial gland, and endometrial epithelium and relatively more weakly in the uterine myometrium on days 11.5 , 13.5, and 17.5 of pregnancy (Figure 6). In the placenta, the protein was localized in trophoblasts of the labyrinth and spongiotrophoblasts. However, giant cells in the junction zone showed significantly lower protein expression (Figure 6). It was interesting to note that high levels of SERPINE2 were found in clusters of glycogen cells in the junction region (Figure 6D,E,F). SERPINE2 was also highly expressed on yolk sac membranes throughout the pregnancy (Figure 6 and data not shown).

\section{Expression of the SERPINE2 protein in the mouse uterus during lactation}

Serpine2 and Plat mRNAs had a tendency to be highly expressed in the mouse uterus during lactation (Figure 7A). The SERPINE2 protein was consistently detected in the postnatal uterus by Western blotting (Figure 7B). Immunohistochemical staining showed that the SERPINE2 protein was strongly expressed in the luminal epithelium in the uterus at postnatal days 1 and 2 (Figure 8B,C). Endometrial SERPINE2 expression was also high even on postnatal day 14 (Figure 8D). The circular and longitudinal layers of the myometrium had weak SERPINE2 expression on postnatal days 1 and 2 in addition to the part around large vessels which had very high SERPINE2 expression levels (Figure 8B,C). However, SERPINE2 expression in the longitudinal muscle layer showed an increased signal on postnatal day 14 (Figure 8D). 


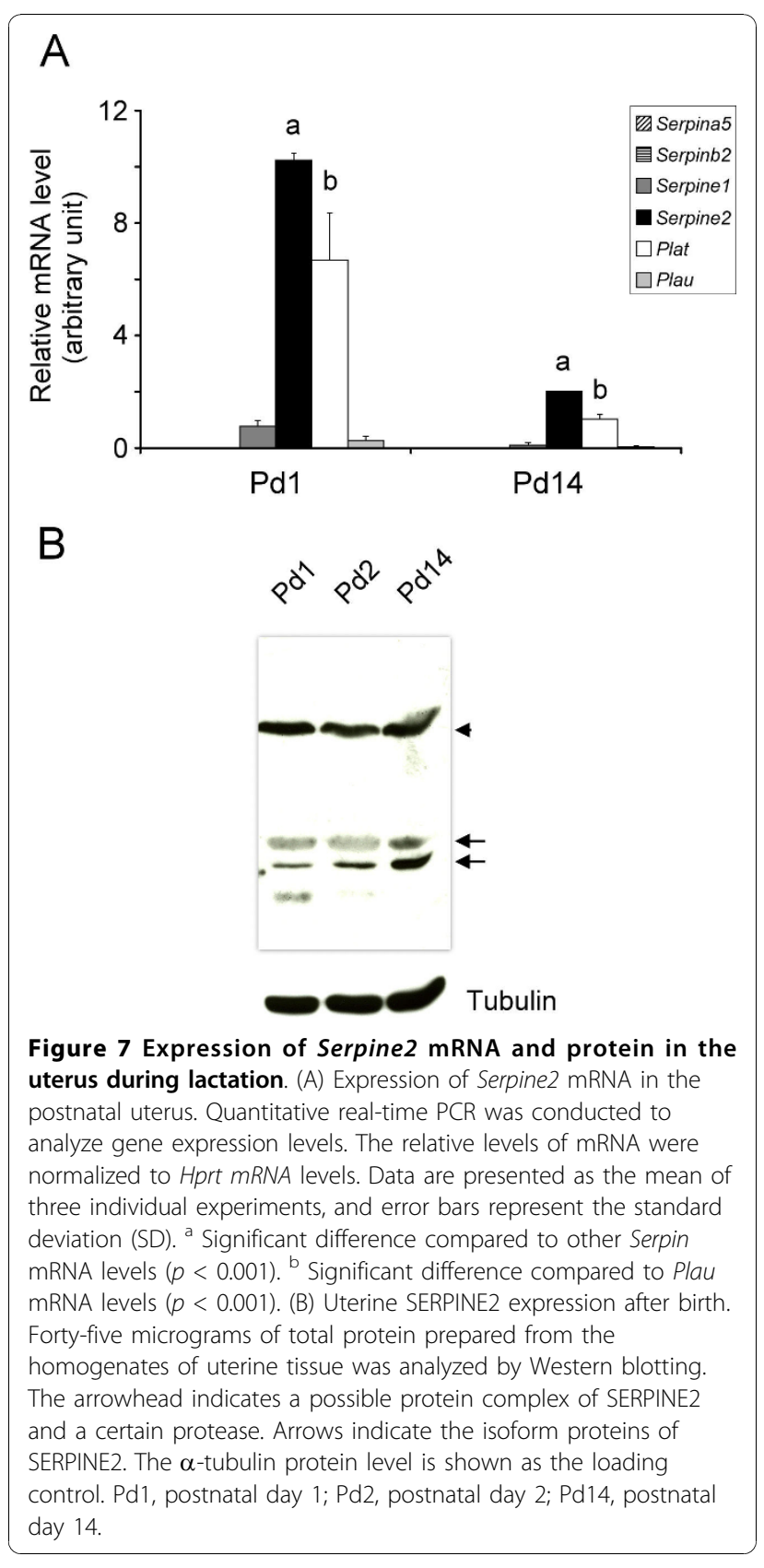

\section{Discussion}

In this study, we demonstrated that SERPINE2 is one of the major PA inhibitors that exists in the mouse placenta and uterus, where it is extensively expressed in various cell types. SERPINE2 is highly expressed in decidual stroma cells during embryo implantation and throughout placentation. It is expressed in labyrinthine trophoblasts and spongiotrophoblasts in the placenta. Intriguingly, giant cells expressed less SERPINE2 in the junction zone, while a group of glycogen cells immediately near the giants cells prominently expressed SERPINE2.
Giant cells in the mesometrial zone, which are differentiated from cells of the ectoplacental cone [26,27], largely expressed SERPINE2, while giant cells' SERPINE2 expression in the antimesometrial zone was low on day 7.5 of early pregnancy (Figure 4). Cells of the ectoplacental cone are precursors of the spongiotrophoblast layer. Indeed, SERPINE2 was prominently expressed in the spongiotrophoblast layer (Figure 6).

SERPINE2 can regulate the activity of serine proteases; thus, it is most likely involved in tissue remodeling. Tissue remodeling is an important biological event for many reproductive processes occurred in the ovary, uterus, and placenta, such as, follicle growth, ovulation, estrous cycle, implantation, and placentation. SERPINE2 is previously demonstrated to be upregulated primarily in dominant follicles during follicle growth $[28,29]$ and during ovulation [30]. However, relatively little work has been done in the uterus. Although, in rats, Serpine 2 mRNA is exclusively expressed in the endometrial stroma and is upregulated at the time of implantation [17], the Serpine 2 mRNA and protein, in mice, is primarily detected in the glandular and luminal cells and is also upregulated at the implantation. The results suggest a role for SERPINE2 in regulating tissue remodeling during implantation.

The cell migration and invasion, the well-known events during placentation, is tightly regulated by proteases and their cognate protease inhibitors [27]. SERPINE2 is widely expressed in various cell types throughout placentation, indicating that this protein is involved in tissue remodeling during placental development.

Our SERPINE2 antiserum detected two major SERPINE2 isoforms in the uterus and placenta. In a protein database search conducted with Basic Local Alignment Search Tool (BLAST) algorithms (http:// www.ncbi.nlm.nih.gov/BLAST) against a non-redundant database using the SERPINE2 protein sequence (Swiss-Prot Q07235) as the query, three isoforms were revealed with the accession numbers of $\mathrm{gb}$ | EDL16269.1|, gb|EDL16267.1|, and gb|EDL16268.1|. The theoretical molecular masses for the three isoforms were $30,812,35,668$, and 44,206 Da, respectively. They are not processed by a signal peptidase. Thus, the mature protein would have a smaller molecular mass. However, the three proteins recognized by the anti-SERPINE2 antiserum had larger molecular masses, indicating they may be the glycosylated forms. In fact, SERPINE2 was demonstrated to be expressed as two glycoprotein forms [31]. Many alternatively spliced gene products of SERPINE2 can also be seen on the NCBI AceView website (http://www.ncbi.nlm.nih.gov/ IEB/Research/Acembly/). Previous reports also supported the existence of multiple forms of the SERPINE2 protein among mouse tissues [32]. 

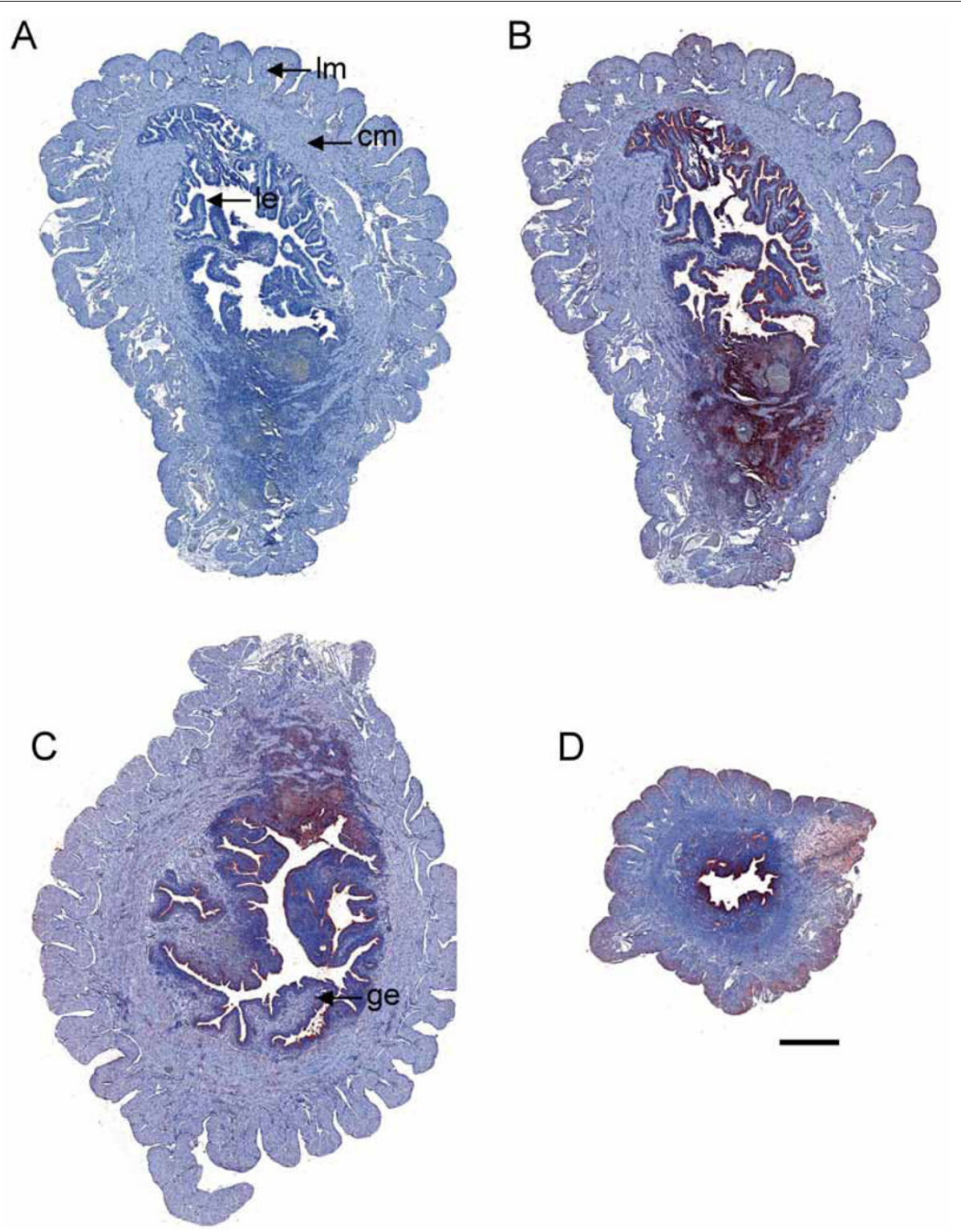

Figure 8 Immunolocalization of SERPINE2 in the uterus during lactation. Uterine sections were immunostained as described in Figure 2. The uterus on postnatal day 1 stained with control antiserum is shown (A). Uteri on postnatal days 1 (B), 2 (C), and 14 (D) were stained with anti-SERPINE2 antiserum. Bar $=500 \mu \mathrm{m} . \mathrm{cm}$, circular muscle; ge, glandular epithelium; le, luminal epithelium; Im, longitudinal muscle.

Previous studies demonstrated that SERPINE2 can form a complex of approximately $75 \mathrm{kDa}$ with PLAU $[14,24,25]$. Also, SERPINE2 was shown to act as a suicide inhibitor of prostasin through formation of an inactive SDS-stable complex with it [12]. Thus, the $75-\mathrm{kDa}$ band detected by the anti-SERPINE2 antiserum may be the complex of SERPINE2 and a certain protease. Prostasin was detected in the monkey placenta [15]. Recently, prostasin was demonstrated to have the ability to regulate human placental trophoblast cell proliferation [33].
Although Serpine2 mRNA and the SERPINE2 protein are highly expressed in the mouse placenta, Serpine1 mRNA seems to be the major PA inhibitor found there. Similarly, SERPINE1 mRNA has higher expression levels than those of SERPINE2 mRNA in the human placenta throughout the three trimesters as demonstrated by quantitative real-time PCR (our unpublished data). The human SERPINE1 protein was intensely stained in trophoblasts invading the decidua and myometrium and was suggested to be a marker for invading trophoblasts 
[34], while the human SERPINE2 protein was primarily observed in the chorionic membrane and trophoblastic epithelium [16].

In our study, we found that Serpinb2 mRNA was not expressed or was below detection in the placenta and uterus during pregnancy. However, the SERPINB2 protein is expressed in the human placenta [34,35]. SERPINB2 was detected in the cytoplasm of villous syncytiotrophoblasts but not of villous cytotrophoblasts or invading trophoblasts [34].

Our anti-SERPINE2 antibody was very sensitive in detecting tissues in which there was trace expression of SERPINE2, even better than the commercial antibody which uses an Escherichia coli-expressed protein as the immunogen (data not shown). Weak or very low levels of SERPINE2 in the monkey endometrium and placenta in a previous study [15] may have resulted from the fact that they used the peptide or E. coli-expressed protein as the immunogen which is often not in the native conformation of a protein. We used a purified native protein as the immunogen; thus, we had a more-specific and -sensitive antiserum.

In an in situ hybridization study, rat Serpine 2 mRNA was found to be primarily localized in endometrial stromal cells of the rat uterus [17]. We found that our antiSERPINE2 antibody could cross-react well to rat uterine SERPINE2. Rat uterine SERPINE2 expression and localization were primarily in the endometrial epithelium, similar to the mouse uterus during the estrous cycle (Additional file 2, Figure S2). In fact, SERPINE2 was also detected in the human uterine endometrium, myometrium (our unpublished data), and placenta [16]. Thus, SERPINE2 must play some roles in uterine tissue remodeling in the PA system, since SERPINE2 is the major PA inhibitor in the uterus.

In conclusion, the SERPINE2 protein is the most highly expressed PA inhibitor in the mouse uterus but is second one in the placenta. The cellular localization of SERPINE2 in the mouse placenta and uterus suggests that SERPINE2 may play important roles in PA-modulated tissue remodeling.

\section{Additional material}

Additional file 1: Supplemental Figure 1. Purification and identification of SERPINE2 from the mouse seminal vesicle fluid.

Additional file 2: Supplemental Figure 2. Expression of the SERPINE2 protein in the rat uterus.

\section{Acknowledgements}

This work was supported by grants from Mackay Memorial Hospital (MMH 9929 and MMH E-99004), Taipei, Taiwan.

\section{Author details}

${ }^{1}$ Department of Biotechnology and Laboratory Science in Medicine, National Yang-Ming University, Taipei, Taiwan. ${ }^{2}$ Department of Medical Research, Mackay Memorial Hospital, Taipei, Taiwan. ${ }^{3}$ Graduate Institute of Biotechnology, National Taipei University of Technology, Taipei, Taiwan.

\section{Authors' contributions}

SRC carried out the Western blotting and real-time PCR analyses, and drafted the manuscript. SHL participated in the design of the study and helped draft the manuscript. CHL carried out protein purification, antibody production, and immunohistochemistry. EITC conceived of the study, and participated in the project design and coordination. All authors read and approved the final manuscript.

\section{Competing interests}

The authors declare that they have no competing interests.

Received: 29 June 2010 Accepted: 27 October 2010

Published: 27 October 2010

\section{References}

1. Vassalli JD, Sappino AP, Belin D: The plasminogen activator/plasmin system. J Clin Invest 1991, 88(4):1067-1072.

2. Ebisch IM, Thomas CM, Wetzels AM, Willemsen WN, Sweep FC, SteegersTheunissen RP: Review of the role of the plasminogen activator system and vascular endothelial growth factor in subfertility. Fertil Steril 2008, 90(6):2340-2350.

3. Saksela O, Rifkin DB: Cell-associated plasminogen activation: regulation and physiological functions. Annu Rev Cell Biol 1988, 4:93-126.

4. Casslen B, Astedt B: Occurrence of both urokinase and tissue plasminogen activator in the human endometrium. Contraception 1983, 28(6):553-564.

5. Svanberg $L$, Astedt B: Release of plasminogen activator from normal and neoplastic endometrium. Experientia 1979, 35(6):818-819.

6. Hofmann GE, Glatstein I, Schatz F, Heller D, Deligdisch L: Immunohistochemical localization of urokinase-type plasminogen activator and the plasminogen activator inhibitors 1 and 2 in early human implantation sites. Am J Obstet Gynecol 1994, 170(2):671-676.

7. Bogic LV, Ohira RH, Yamamoto SY, Okazaki KJ, Millar K, BryantGreenwood GD: Tissue plasminogen activator and its receptor in the human amnion, chorion, and decidua at preterm and term. Biol Reprod 1999, 60(4):1006-1012.

8. Feng Q, Liu Y, Liu K, Byrne S, Liu G, Wang X, Li Z, Ockleford CD: Expression of urokinase, plasminogen activator inhibitors and urokinase receptor in pregnant rhesus monkey uterus during early placentation. Placenta 2000, 21(2-3):184-193.

9. Hu ZY, Liu YX, Liu K, Byrne S, Ny T, Feng Q, Ockleford CD: Expression of tissue type and urokinase type plasminogen activators as well as plasminogen activator inhibitor type- 1 and type- 2 in human and rhesus monkey placenta. J Anat 1999, 194(2):183-195.

10. Teesalu T, Blasi F, Talarico D: Expression and function of the urokinase type plasminogen activator during mouse hemochorial placental development. Dev Dyn 1998, 213(1):27-38.

11. Teesalu T, Blasi F, Talarico D: Embryo implantation in mouse: fetomaternal coordination in the pattern of expression of UPA, UPAR, PAI-1 and alpha 2MR/LRP genes. Mech Dev 1996, 56(1-2):103-116.

12. Chen LM, Skinner ML, Kauffman SW, Chao J, Chao L, Thaler CD, Chai KX: Prostasin is a glycosylphosphatidylinositol-anchored active serine protease. J Biol Chem 2001, 276(24):21434-21442.

13. Scott RW, Bergman BL, Bajpai A, Hersh RT, Rodriguez H, Jones BN, Barreda C, Watts S, Baker JB: Protease nexin. Properties and a modified purification procedure. J Biol Chem 1985, 260(11):7029-7034.

14. Vassalli JD, Huarte J, Bosco D, Sappino AP, Sappino N, Velardi A, Wohlwend A, Erno H, Monard D, Belin D: Protease-nexin I as an androgen-dependent secretory product of the murine seminal vesicle. EMBO J 1993, 12(5):1871-1878.

15. Lin HY, Zhang H, Yang Q, Wang HX, Wang HM, Chai KX, Chen LM, Zhu C: Expression of prostasin and protease nexin-1 in rhesus monkey (Macaca mulatta) endometrium and placenta during early pregnancy. J Histochem Cytochem 2006, 54(10):1139-1147. 
16. White EA, Baker JB, McGrogan M, Kitos PA: Protease nexin 1 is expressed in the human placenta. Thromb Haemost 1993, 69(2):119-123.

17. Kim NK, Choi MJ, Chung HM, Sohn TJ, Hwang SG, Oh D, Lee HH, Lee YH, Ko J: Increased expression and localization of a serine protease inhibitor, protease nexin-1 (PN-1), in the ovary and uterus during implantation in rat. Thromb Res 2001, 103(2):135-142.

18. Li SH, Lee RK, Lin MH, Hwu YM, Lu CH, Chen YJ, Chen HC, Chang WH, Chang WC: SSLP-1, a secreted Ly- 6 protein purified from mouse seminal vesicle fluid. Reproduction 2006, 132(3):493-500.

19. Rugh R: The Mouse: Its Reproduction and Development. New York: Oxford University Press; 1994.

20. Koto M, Miwa M, Togashi M, Tsuji K, Okamoto M, Adachi J: [A method for detecting the optimum day for mating during the 4-day estrous cycle in the rat; measuring the value of electrical impedance of the vagina]. Jikken Dobutsu 1987, 36(2):195-198.

21. Livak KJ, Schmittgen TD: Analysis of relative gene expression data using real-time quantitative PCR and the 2(-Delta Delta C(T)) Method. Methods 2001, 25(4):402-408.

22. Lin MH, Lee RK, Hwu YM, Lu CH, Chu SL, Chen YJ, Chang WC, Li SH: SPINKL, a Kazal-type serine protease inhibitor-like protein purified from mouse seminal vesicle fluid, is able to inhibit sperm capacitation. Reproduction 2008, 136(5):559-571.

23. Towbin $\mathrm{H}$, Staehelin T, Gordon J: Electrophoretic transfer of proteins from polyacrylamide gels to nitrocellulose sheets: procedure and some applications. Proc Natl Acad Sci USA 1979, 76(9):4350-4354.

24. Howard EW, Knauer DJ: Characterization of the receptor for protease nexin-l:protease complexes on human fibroblasts. J Cell Physiol 1987, 131(2):276-283.

25. Wagner SL, Lau AL, Cunningham DD: Binding of protease nexin-1 to the fibroblast surface alters its target proteinase specificity. J Biol Chem 1989, 264(1):611-615.

26. Cross JC: Genetic insights into trophoblast differentiation and placental morphogenesis. Semin Cell Dev Biol 2000, 11(2):105-113.

27. Cross JC, Werb Z, Fisher SJ: Implantation and the placenta: key pieces of the development puzzle. Science 1994, 266(5190):1508-1518.

28. Bedard J, Brule S, Price CA, Silversides DW, Lussier JG: Serine protease inhibitor-E2 (SERPINE2) is differentially expressed in granulosa cells of dominant follicle in cattle. Mol Reprod Dev 2003, 64(2):152-165.

29. Fayad T, Levesque V, Sirois J, Silversides DW, Lussier JG: Gene expression profiling of differentially expressed genes in granulosa cells of bovine dominant follicles using suppression subtractive hybridization. Biol Reprod 2004, 70(2):523-533.

30. Hagglund AC, Ny A, Liu K, Ny T: Coordinated and cell-specific induction of both physiological plasminogen activators creates functionally redundant mechanisms for plasmin formation during ovulation. Endocrinology 1996, 137(12):5671-5677.

31. Guenther J, Nick H, Monard D: A glia-derived neurite-promoting factor with protease inhibitory activity. EMBO J 1985, 4(8):1963-1966.

32. Mansuy IM, van der Putten $H$, Schmid P, Meins M, Botteri FM, Monard D: Variable and multiple expression of Protease Nexin-1 during mouse organogenesis and nervous system development. Development 1993, 119(4):1119-1134.

33. Fu YY, Gao WL, Chen M, Chai KX, Wang YL, Chen LM: Prostasin regulates human placental trophoblast cell proliferation via the epidermal growth factor receptor signaling pathway. Hum Reprod 2010, 25(3):623-632.

34. Feinberg RF, Kao LC, Haimowitz JE, Queenan JT Jr, Wun TC, Strauss JF, Kliman HJ: Plasminogen activator inhibitor types 1 and 2 in human trophoblasts. PAl-1 is an immunocytochemical marker of invading trophoblasts. Lab Invest 1989, 61(1):20-26.

35. Astedt B, Hagerstrand I, Lecander I: Cellular localisation in placenta of placental type plasminogen activator inhibitor. Thromb Haemost 1986, 56(1):63-65

doi:10.1186/1477-7827-8-127

Cite this article as: Chern et al: Spatiotemporal expression of the serine protease inhibitor, SERPINE2, in the mouse placenta and uterus during the estrous cycle, pregnancy, and lactation. Reproductive Biology and Endocrinology 2010 8:127.

\section{Submit your next manuscript to BioMed Central and take full advantage of:}

- Convenient online submission

- Thorough peer review

- No space constraints or color figure charges

- Immediate publication on acceptance

- Inclusion in PubMed, CAS, Scopus and Google Scholar

- Research which is freely available for redistribution

Submit your manuscript at www.biomedcentral.com/submit
Biomed Central 